\title{
¿DEBÍA EL "NUEVO IFAI" PROMOVER UNA ACGIÓN DE INCONSTITUCIONALIDAD CONTRA LA LEY TELECOM? COMENTARIOS EN TORNO A LA CONSTRUCGIÓN DE LA CONFIANZA INSTITUGIONAL
}

\author{
María Grisel SalaZar ReBOlLEDO*
}

\begin{abstract}
SUMARIO: I. Introducción. II. La reforma de 2014: la construcción de un "nuevo IFAI". III. La Ley Telecom y la demanda de intervención del IFAI. IV. Posibles consecuencias de la postura del IFAI respecto a la Ley Telecom. V. Bibliografia.
\end{abstract}

\section{INTRODUCGIÓN}

Desde sus orígenes, la política de transparencia y acceso a la información en México ganó amplió reconocimiento social e internacional. Ello se debió, en gran medida, a la calidad y los alcances de la normatividad creada, que basaban el establecimiento de un sistema de acceso sólido y novedoso en cuyo centro se colocó un órgano especializado: el hoy llamado Instituto de Acceso a la Información y Protección de Datos Personales (IFAI). El IFAI nació revestido de una gran dosis de legitimidad, por su pluralidad de origen, por su original diseño, reconocido por organismos internacionales como la Organización de Estados Americanos; y por el acompañamiento de organizaciones sociales, atentas al desempeño del IFAI como órgano y a la trasparencia como proyecto de largo aliento, sumó legitimidad y confianza.

Como es natural, a lo largo de sus primeros doce años de vida, las limitaciones y alcances del acceso a la información y de su órgano garante se hicieron evidentes, de tal suerte que pronto aparecieron reformas encaminadas a mejorar su funcionamiento. Por mencionar algunas, en 2006 se llevó a cabo la primera reforma constitucional en la materia, con el objeto de garantizar un piso mínimo para construir una política nacional de transparencia; ${ }^{1}$ posteriormente, en 2010, el IFAI adquirió la facultad

* Máster en ciencia política por la Universidad de Salamanca, España; licenciada en política y administración pública por El Colegio de México; e-mail: maria.salazar@alumnos. cide.edu

1 Merino, Mauricio, "Muchas políticas y un solo derecho", en López-Ayllón, Sergio (ed.), Democracia, transparencia y Constitución, México, IFAI-UNAM, 2006, y López Ayllón, Ser- 
de velar por la protección de datos personales. Pero fue en 2014 cuando se emprendió la primera gran reforma constitucional en acceso a la información, con el IFAI en el centro de los cambios, apuntalando los flancos débiles de origen, fortaleciendo los aspectos que mostraban señales de desgaste y añadiendo instrumentos para robustecerlo institucionalmente, permitiéndole, en lo formal, estar a la altura de sus atribuciones originales y de las que adquirió en momentos posteriores.

Bajo este renovado modelo normativo, el recién remodelado IFAI se enfrentó a la disyuntiva de promover una acción de inconstitucionalidad en contra de la Ley Federal de Telecomunicaciones y Radiodifusión (Ley Telecom).

El objetivo de este texto es discutir las consecuencias de que el "nuevo IFAI" haya desechado promover este recurso ante la Suprema Corte de Justicia de la Nación (SCJN). Se sostiene que la legitimidad de que gozaba el IFAI, al menos durante gran parte de sus primeros doce años de vida, estaba basada en el reconocimiento a su intercambio constante con grupos ciudadanos y a la postura progresista de sus decisiones. Este reconocimiento ha sido otorgado ampliamente por organizaciones de la sociedad civil y otros especialistas en el tema. Se dice que desechar la posibilidad de interponer una acción de inconstitucionalidad en torno a un tema conflictivo supuso debilitar este reconocimiento al renunciar a ejercer uno de los instrumentos más importantes que recibía a partir de la última reforma constitucional. Al mismo tiempo, la renovación total de los comisionados que implicó el cambio legislativo, así como la modificación de las reglas del juego hacen que el IFAI esté nuevamente construyéndose una reputación, si no completamente nueva, sí en términos de las decisiones que toma en esta etapa de transición institucional. De este modo, las primeras señales que envíe en términos de sus resoluciones serán referente importante para la conservar la confianza ciudadana depositada en este órgano colegiado y el reconocimiento a sus prácticas y resoluciones. La decisión en torno a la promoción de una acción de inconstitucionalidad contra la Ley Telecom provee un ejemplo ilustrativo de cómo se construye, se conserva o se pierde la confianza y la legitimidad institucional.

gio, "El marco normativo de la transparencia y el acceso a la información en México", en Cejudo, Guillermo et al. (coords.), La política de la transparencia en México. Instituciones, logros y desafios, México, CIDE, 2012. 
En la primera sección del trabajo se repasa de manera breve el contenido de la reforma constitucional de 2014, enfatizando los elementos que fortalecieron al IFAI en el ámbito formal. En la segunda parte, se describen los elementos conflictivos de la Ley Telecom que dieron origen a las demandas de que el IFAI interviniera, para salvaguardar el acceso a la información y la protección de datos personales. Asimismo, se presentan las posturas que fundamentaban el proyecto de demanda, y los argumentos que basaron la resolución de que el IFAI no promovería la acción de inconstitucionalidad; y finalmente, en la tercera parte se adelantan algunas posibles consecuencias de esta decisión.

\section{LA REFORMA DE 2014: LA CONSTRUCGIÓN DE UN “NUEVO IFAI”}

Después de casi dos años de discusión en el Congreso, el 7 de febrero de 2014 se aprobó una amplia reforma constitucional en materia de acceso a la información, cuyo énfasis estaba puesto en modificar varios elementos institucionales del IFAI: su integración, sus facultades y los alcances de sus decisiones.

Las implicaciones principales de la reforma fueron: a) se otorgó plena autonomía al IFAI y a los órganos garantes estatales, reconociéndosele personalidad jurídica y patrimonio propios; b) sus resoluciones adquirieron el carácter de definitivas e inatacables; c) se amplió de cinco a siete el número de comisionados integrantes del pleno; d) se incrementó la gama de sujetos obligados, y e) se otorgó al IFAI la facultad de promover acciones de inconstitucionalidad cuando se promulguen leyes o tratados internacionales que vulneren o limiten el derecho de acceso a la información y la protección de datos personales.

El IFAI comenzó a funcionar en mayo de 2014 bajo este nuevo arreglo institucional, con un pleno de comisionados recién nombrados. La transformación constitucional del IFAI y de sus integrantes generó amplios desafíos: en términos formales, se buscó eliminar los obstáculos para que el órgano colegiado pudiera funcionar de manera autónoma e independiente, y superar las limitaciones que se fueron evidenciando $-\mathrm{y}$ surgiendo - a lo largo de los primeros doce años de la entrada en vigor de la Ley Federal de Transparencia (LFT).

Desde sus orígenes, la articulación del acceso a la información como política pública ha estado acompañada por académicos, especialistas y 
representantes de la sociedad civil organizada, que se han mantenido pendientes del desempeño del IFAI y del ejercicio del acceso a la información. ${ }^{2}$ Como es natural, a partir de que la LFT entró en vigor, tanto sujetos obligados como solicitantes "apredieron a jugar el juego de la transparencia", 3 es decir, han ido ajustando sus estrategias para satisfacer sus intereses: por un lado, los sujetos obligados satisfacen en forma más ágil las solicitudes (y también son más aptos para encontrar rodeos cuando otorgar la información solicitada resulta incómodo); y por otro, los solicitantes han aprendido a formular de manera más precisa sus peticiones. Así, la reforma de 2014, buscaba, por un lado, atender temas que se habían dejado en el tintero desde la redacción inicial de la LFT en 2002, y por el otro, hacer frente a los obstáculos organizacionales, de acceso, y de funcionamiento de todo el sistema de transparencia y protección de datos que han emergido a lo largo de estos años. Por sus alcances, la reforma de 2014 originó altas expectativas sobre la forma en la que funcionaría el IFAI, revestido de nuevos recursos institucionales.

\section{LA LEY TELECOM Y LA DEMANDA DE INTERVENGIÓN DEL IFAI}

Uno de los primeros desafíos a los que se enfrentó el nuevo IFAI bajo su nuevo diseño institucional vino aparejado con la aprobación de la Ley Telecom, el 14 de julio de 2014. Esta ley incluye ciertas disposiciones problemáticas que, a decir de varios especialistas, encierran el riesgo de atentar contra el acceso a la información y la protección de datos personales. Diversos expertos y representantes de la sociedad civil organizada coincidían en que el primer gran reto del nuevo IFAI era pronunciarse en contra del contenido en debate, valiéndose de uno de los recursos más relevantes que le otorgaba la reforma de 2014: la promoción de una acción de inconstitucionalidad ante la SCJN; hacerlo daría muestra de su actuar inde-

2 Ejemplos de esas organizaciones, permanentes o temporales, han sido: el Grupo Oaxaca, en el momento de formulación de la LFT; y posteriormente el Colectivo por la Transparencia y la Red por la Rendición de Cuentas, y sus partes integrantes de manera individual, entre otros.

3 Salazar, Grisel, "Comentario a la propuesta de reforma constitucional en materia de transparencia aprobada en 2012 por el Senado", Boletín Mexicano de Derecho Comparado, núm. 137, mayo-agosto de 2013, p. 783.

D. R. (C) 2015. UNAM, Instituto de Investigaciones Jurídicas,

Boletín Mexicano de Derecho Comparado, núm. 142, pp. 385-397 
pendiente y sería la vara con que se mediría su compromiso con el acceso a la información y la salvaguarda de los datos personales.

Las disposiciones conflictivas de la Ley Telecom se encuentran en los artículos 30, 189 y 190, en los fragmentos que se reproducen a continuación:

Artículo 30. ...Las entrevistas serán grabadas y almacenadas en medios electrónicos, ópticos o de cualquier otra tecnología, manteniéndose como información reservada, salvo para las otras partes en los procedimientos seguidos en forma de juicio, los demás comisionados, el Contralor Interno y el Senado de la República en caso de que esté sustanciando un procedimiento de remoción de un comisionado...

Artículo 189. Los concesionarios de telecomunicaciones y, en su caso, los autorizados y proveedores de servicios de aplicaciones y contenidos están obligados a atender todo mandamiento por escrito, fundado y motivado de la autoridad competente en los términos que establezcan las leyes...

Artículo 190. Los concesionarios de telecomunicaciones y, en su caso, los autorizados deberán:

I. Colaborar con las instancias de seguridad, procuración y administración de justicia, en la localización geográfica, en tiempo real, de los equipos de comunicación móvil, en los términos que establezcan las leyes...

II. Conservar un registro y control de comunicaciones que se realicen desde cualquier tipo de línea que utilice numeración propia o arrendada, bajo cualquier modalidad, que permitan identificar con precisión los siguientes datos: [nombre y domicilio del suscriptor, tipo de comunicación, datos necesarios para rastrear e identificar el origen y destino de las comunicaciones, número de destino, datos necesarios para determinar la fecha hora y duración de la comunicación, identificación y características técnicas de los dispositivos, ubicación digital del posicionamiento geográfico de las lineas telefónicas]...

III. Entregar los datos conservados a las autoridades a que se refiere el artículo 189 de esta Ley. ${ }^{4}$

En términos generales, tanto los comisionados que elaboraron el proyecto de demanda para promover la acción como aquellos especialistas que desde los medios de comunicación y las redes sociales también reclamaban la intervención del IFAI, esgrimían como argumento que el ar-

4 Ley Federal de Telecomunicaciones y Radiodifusión, 14 de julio de 2014. Los énfasis son propios. 
tículo 30 de la Ley Telecom incluye un obstáculo al ejercicio del derecho de acceso a la información, por la disposición de reserva incluida; mientras que los artículos 189 y 190, en las fracciones citadas, encerraban el riesgo de violar el derecho a la protección de datos personales por la posibilidad de geolocalización de dispositivos móviles, y la disposición de entregar y conservar esta información.

A lo largo de varias semanas el IFAI preparó su postura en torno al tema. Durante el proceso, un grupo conformado por 219 organizaciones de la sociedad civil hicieron un llamado al IFAI para presentar acción de inconstitucionalidad, ${ }^{5} \mathrm{y}$ le hicieron llegar argumentos que buscaban mostrar la conveniencia de promover este recurso. Finalmente, en la sesión del pleno del 13 de agosto de 2014, fecha en la que vencía el plazo para que el organismo tomara una decisión, con 3 votos a favor y 4 en contra, se determinó no interponer una acción de inconstitucionalidad ante la Suprema Corte de Justicia.

Los comisionados Óscar Guerra, Areli Cano y Joel Salas fueron quienes se pronunciaron a favor de que el IFAI promoviera la acción de inconstitucionalidad. Dentro de su posicionamiento, la comisionada Cano argumentó que:

Esta hipótesis [contenida en el artículo 30 de la Ley Telecom] implica una reserva general de la información, lo cual restringe el derecho a saber por parte de las personas, ya que de manera genérica establece una reserva de la información en posesión de los sujetos obligados, sin precisar las razones específicas de orden público que permitan clasificar todas las entrevistas que lleven a cabo los comisionados del Instituto Federal de Telecomunicaciones con los representantes de los agentes regulados o, en su caso, el fin y objetivo que se busca con su restricción. ${ }^{6}$

5 Fundar, El IFAI debe presentar acción de inconstitucionalidad, México, 14 de julio de 2014. http://fundar.org.mx/el-ifai-debe-presentar-accion-de-inconstitucionalidad-en-contra-de-la-ley-de-tele comunicacion-y-radiodifusion/\#.VBnrQvl5OSo (consultada el 13 de septiembre de 2014). Asimismo, la Red en Defensa de los Derechos Digitales hizo llegar al IFAI el estudio llamado "Fundamentos para la interposición de una acción de inconstitucionalidad en contra del artículo 190 de la Ley Federal de Telecomunicaciones y Radiodifusión” disponible en http://fundar.org.mx/mexico/pdf/ANEXOTECNICOIFAILETTELECOM.pdf, (consultada el 15 de septiembre de 2014).

6 Posicionamiento de los Comisionados del IFAI sobre la inconstitucionalidad de los artículos 30, 189 y 190, fracciones I, II y III de la Ley Federal de Telecomunicaciones y Radiodifusión, México, 
Respecto de los artículos 189 y 190, la comisionada señaló que la Ley Telecom incumple el presupuesto constitucional de derecho a la privacidad contenido en el artículo 16 constitucional, puesto que el artículo 189 "no establece en forma clara y precisa cuáles son las autoridades competentes, ni la materia o los delitos por los cuales se podrán formular las solicitudes correspondientes", y el 190

$[\mathrm{N}]$ o establece las condiciones y circunstancias en que puede efectuarse la localización geográfica ... de equipos de comunicación móvil, debido a que no existe precisión respecto de las "instancias de seguridad" que pueden solicitar este tipo de información; tampoco señala de manera clara, precisa y detallada las circunstancias [ni] el procedimiento a seguir, ni las salvaguardas... para impedir el abuso de esta medida de vigilancia encubierta. ${ }^{7}$

Por su parte, el comisionado Guerra señaló que el artículo 30 de la Ley Telecom:

i) impide el derecho de acceso por el medio menos gravoso, ii) es contrario al principio de máxima publicidad al establecer como regla la negativa de acceso a las entrevistas en comento, y iii) no permite realizar una "prueba de daño" respecto del contenido de cada entrevista. ${ }^{8}$

\section{Respecto del artículo189 y 190, señaló que}

vulneran el derecho a la protección de los datos personales consagrado en el artículo 16 constitucional, segundo párrafo, en tanto inhiben la facultad de autodeterminación sobre los datos personales que serán objeto de tratamiento. Adicionalmente, al imponer a los prestadores del servicio de telefonía un plazo de conservación obligatorio de 2 años, se elimina la capacidad del titular de los datos de ejercer su derecho de cancelación y oposición sobre los mismos. ${ }^{9}$

En sentido similar a lo señalado por la Comisionada Cano, Óscar Guerra señaló riesgos en la indefinición de los supuestos de excepción, los

IFAI, 13 de agosto de 2014, p. 2.

7 Ibidem, p. 9.

8 Ibidem, p. 25.

9 Ibidem, p. 27.

D. R.C 2014. UNAM, Instituto de Investigaciones Jurídicas, Boletín Mexicano de Derecho Comparado, núm. 142, pp. 385-397 
sujetos autorizados para acceder a los datos personales en comento, las circunstancias y las finalidades.

El comisionado Joel Salas advirtió que "el mecanismo de control respecto de la actuación del ministerio público... se deja al arbitrio de esta autoridad administrativa tanto la ejecución de la ley como su propio control, quebrantando quizá el principio de separación de poderes...". ${ }^{10}$

La decisión final, contraria a que el IFAI promoviera una acción de inconstitucionalidad, se basó en los argumentos presentados por el resto de los comisionados, que fueron retomados en la intervención de Ximena Puente, comisionada presidenta del IFAI, en diez puntos, que se sintetizan a continuación:

a) Legitimación activa. Puede darse el caso que el Instituto no esté legitimado para perseguir la declaración de inconstitucionalidad. El IFAI sólo está legitimado para interponerla contra normas que vulneren el derecho al acceso a la información pública y la protección de datos personales, por tanto, la demanda que se pretende iniciar puede ser desestimada por falta de legitimación, por estar relacionada con materia de seguridad y procuración de justicia.

b) Improcedencia por estar en trámite otra acción de inconstitucionalidad. Actualmente está en trámite una acción de inconstitucionalidad interpuesta por el IFAI en contra del artículo 303 del Código Nacional de Procedimientos Penales, cuyo contenido está altamente relacionado con el contenido en discusión de la Ley Telecom. De ese modo, se considera que la resolución que tome la SCJN respecto de esta disposición, también se aplicará a los contenidos de la Ley Telecom.

c) Improcedencia de la acción de inconstitucionalidad, en virtud que la misma descansa en omisiones legislativas. Se argumenta, con base en jurisprudencias anteriores, que la SCJN sólo puede actuar como legislador negativo pero no puede obligar a emitir una nueva norma por motivo de omisión.

d) El artículo 30 de la Ley Telecom no es inconstitucional. Se argumenta que no establece una reserva total de la información, pues se "dispone claramente" 11 que de cada entrevista se llevará un registro que con-

$10 \quad$ Ibidem, p. 51.

11 Posicionamiento de los Comisionados del IFAI..., p. 73.

D. R. (C) 2015. UNAM, Instituto de Investigaciones Jurídicas, Boletín Mexicano de Derecho Comparado, núm. 142, pp. 385-397 
tendrá lugar, fecha y hora, y que dicha información deberá publicarse en el portal de Internet del Instituto Federal de Telecomunicaciones.

e) La geolocalización y la entrega de datos sí reúnen los requisitos exigidos en el artículo 16 constitucional, de tal modo que, si se adopta una visión "sistémica" 12 de la disposición normativa, no resultan en un riesgo para la seguridad e intimidad de las personas. Se alega que, contrario a lo señalado, la disposición normativa sí establece de manera precisa la autoridad competente, el mandamiento, el papel de los concesionarios, y los mecanismos ante los que se puede acudir en caso de excesos en la medida.

f) El derecho a la intimidad no es un derecho absoluto. Sus restricciones deben estar previstas en la ley siempre y cuando se persiga un fin legítimo y las injerencias no sean abusivas o arbitrarias. En el caso de la Ley Telecom, el fin que se persigue es la seguridad pública.

g) La medida de geolocalización no es una violación al derecho de privacidad. Según votaciones previas de la SCJN, ésta es un instrumento que "da efectividad a la persecución de determinados delitos, sin que pueda estimarse lesiva de derechos fundamentales", ${ }^{13}$ pues tiene por objeto la localización de equipos de comunicación y no de personas individualmente determinadas.

h) El principio de reserva de ley está indebidamente interpretado. "En el proyecto de demanda se confunde a la reserva de ley con el principio de legalidad, que obliga a que las limitaciones de los derechos humanos se encuentren en una ley en sentido formal y material." ${ }_{14}$

i) La conservación de un registro y control de las comunicaciones de telefonía celular no supone una violación al derecho a la privacidad. Ello, basado en que la Ley Telecom establece expresamente las excepciones a la protección de datos, "sin que sea necesario que se definan mayores parámetros respecto de la misma". ${ }^{15}$

j) La entrega de datos contenidos en el registro no supone una violación al derecho a la privacidad. Una acción de inconstitucionalidad no puede promoverse con base en las "suposiciones o expectativas sobre la forma en que será aplicada una norma en un caso concreto". ${ }^{16}$

\footnotetext{
12 Ibidem, p. 75.

13 Ibidem, p. 85.

14 Ibidem, p. 88.

15 Ibidem, p. 90.

$16 \quad$ Ibidem, p. 92.
} 


\section{Posibles GONSEGUENCiAS DE LA POSTURA DEL IFAI RESPECTO A LA LEY TELECOM}

Revestido de las crecidas facultades que le otorgaba la reforma constitucional de febrero de 2014, y con un pleno renovado, la primera gran decisión del nuevo IFAI en términos de trascendencia y de resonancia pública dejó una sensación de incomodidad e insatisfacción, sobre todo entre las organizaciones ciudadanas articuladas en torno al tema de la transparencia y la rendición de cuentas, y otros grupos de expertos, incluyendo integrantes de órganos garantes estatales, que manifestaron públicamente su desencanto en diversos medios de comunicación, y en algunos casos, dentro del seno mismo del IFAI. ${ }^{17}$

A la luz de los argumentos vertidos por el propio IFAI para desechar la posibilidad de promover una acción de inconstitucionalidad, de la forma en que se desenvolvió el proceso, y de las reacciones generadas, sostenemos que la decisión de no intervenir en esta materia vulneró la legitimidad y la confianza ciudadana depositada en el IFAI al menos por cuatro razones:

a) Desencanto entre los grupos sociales y académicos especializados. Como se ha venido señalando en este texto, en gran medida, la instalación definitiva de la transparencia y el acceso a la información en la agenda pública mexicana se debe a la existencia e intervención continua de grupos independientes, atentos a la forma en que estos temas han cristalizado como políticas públicas. Sin pretender que las recomendaciones emitidas por estos grupos deban ser integradas a la letra en las resoluciones del IFAI, los comisionados opuestos al proyecto de demanda se desmarcaron respecto de los estudios realizados por organizaciones sociales respecto de la conveniencia de la intervención y los calificaron como "criterios

17 Tal fue el caso del Colectivo por la Transparencia, que en la sesión pública del 21 de agosto de 2014, realizó un reclamo abierto a los comisionados del IFAI por la resolución tomada; del consejero consultivo de la Comisión de Transparencia del Estado de Oaxaca, Alejandro Cruz, que publicó su postura en la página de la Rendición de Cuentas, y de los comisionados del InfoDF, órgano que buscó interponer por su cuenta la acción de inconstitucionalidad, aunque no prosperó. Para una compilación de éstas y otras notas críticas, consultar el micrositio Red por la Rendición de Cuentas, Acción de inconstitucionalidady Reforma Telecom, http://rendiciondecuentas.org.mx/accion-de-inconstitucionalidad-y-reforma-telecom/ (consultada el 10 de septiembre de 2014).

D. R. (C) 2015. UNAM, Instituto de Investigaciones Jurídicas,

Boletín Mexicano de Derecho Comparado, núm. 142, pp. 385-397 
orientadores". ${ }^{18}$ Esta postura establece un distanciamiento del organismo respecto de los grupos especializados con los que, en ocasiones anteriores, se habían establecido proyectos de intercambio y apertura, y se lanza una señal de poca preocupación por recoger las opiniones e inquietudes de representantes de la sociedad civil organizada y de grupos de expertos, marcando un nuevo derrotero en la relación del IFAI con ellos.

Pero también se lanza una señal negativa hacia la ciudadanía en sentido amplio. El funcionamiento de las políticas de transparencia gira en torno a solicitantes activos, cuya presencia depende de que exista un nivel de confianza institucional, por mínimo que sea. Si el solicitante desconfía de que hay garantías de que su derecho de acceso será respetado por los sujetos obligados, o defendido por el IFAI, probablemente no hará uso de los mecanismos para solicitar información. El IFAI funge como bisagra entre los sujetos obligados y los solicitantes dentro de las políticas de acceso a la información, es por ello que la confianza ciudadana depositada en él desempeña un papel crucial en la legitimidad de estas políticas, cuya razón de ser se la otorgan los usuarios activos.

b) Percepción de un IFAI fragmentado. Lo cerrado de la votación y la orientación de los argumentos vertidos tanto por los comisionados que apoyaban la promoción de acción de inconstitucionalidad como por quienes se oponían a ella dan la sensación de que el pleno del IFAI está desarticulado, si no es que confrontado, en la concepción del papel que este organismo debe desempeñar dentro del entramado político. Lo anterior, inevitablemente se vinculó con la posibilidad de que las orientaciones partidistas estuvieran anteponiéndose a la discusión sustantiva sobre la salvaguarda del derecho de acceso a la información y a la protección de datos personales.

c) Percepción de un IFAI conservador. Por su naturaleza, es deseable que los órganos que tienen una función de defensoría de algún derecho asuman una postura progresista en lo concerniente a la salvaguarda de éste. Si bien el derecho a la vida privada no es un derecho absoluto, y se reconoce que el derecho de acceso a la información debe tener límites, la función del IFAI debe ser la expansión de ambos, contraponiéndose a cualquier

18 Ángel Cabrera, "IFAI rechaza ejercer inconstitucionalidad contra Ley Telecom", 24 horas, 13 de agosto de 2014, http://wrere.24-horas.mx/ifai-rechaza-ejercer-inconstitucionalidadcontra-ley-telecom/(consultada el 17 de septiembre de 2014). 
situación riesgosa que atente en su contra, aunque ésta sea hipotética o potencial. Los argumentos por los que se desechó la promoción de la acción de inconstitucionalidad se formularon desde una visión de defensa de status quo, tomando a las amenazas como hechos improbables, asumiendo que no hace falta ser explícitos en excepciones e indefiniciones, y privilegiando la concreción de otras políticas y otros principios ajenos al IFAI por encima de aquellos que justifican su existencia como institución. Sin restar importancia a los fines de "seguridad nacional", lo que se argumenta aquí es que el IFAI debe cerciorarse que en todas las áreas de política se garanticen los derechos de acceso a la información y de protección de datos personales, por tanto, su función debe ser ejercer un contrapeso progresista desde su ámbito de expertice. A relativamente pocos años de la puesta en marcha de la política de transparencia, y menos años aún de la de protección de datos personales, no puede asumirse, ni siquiera bajo argumentos de técnica jurídica, que es innecesario establecer definiciones claras, atribuciones precisas y límites concretos a normas que entran en conflicto con estas garantías.

d) Precedente de resolución. Como se mencionó líneas más arriba, la renovación normativa y directiva del IFAI abrió una nueva etapa en lo relativo a la construcción de una reputación. De este modo, la primera gran decisión del nuevo IFAI podrá ser tomada como referente, tanto por las organizaciones especializadas no gubernamentales, como por el mismo órgano colegiado para decisiones posteriores. Las señales enviadas por esta resolución hablan de un IFAI que aplazó su resolución al último momento, desmarcado de las voces ciudadanas y más orientado a respaldar los planes de gobierno (en este caso, las políticas de seguridad que subyacen a la Ley Telecom) que a empujar hasta el límite la defensa de los derechos bajo su tutela. En ese sentido, la confianza que fue construyéndose el IFAI con sus primeras decisiones - y que posteriormente se debilitó - vuelve a estar en riesgo, pero esta vez con la diferencia de que, técnicamente, los obstáculos normativos o facultativos fueron removidos por la reforma de 2014. Lo alarmante es notar cómo, a muy poco tiempo de puesta en marcha esta renovación institucional, la brecha entre el funcionamiento formal y el real se ha empezado a ampliar. 


\section{BIBLIOGRAFÍA}

CEJUDO, Guillermo et al. (coords.), La política de la transparencia en México. Instituciones, logros y desafios, México, CIDE, 2012.

CABRERA, Ángel, "IFAI rechaza ejercer inconstitucionalidad contra Ley Telecom", 24 horas, 13 de agosto de 2014, http://wwr.24-horas.mx/ifairechaza-ejercer-inconstitucionalidad-contra-ley-telecom/(consultada el 17 de septiembre de 2014).

Fundar, El IFAI debe presentar acción de inconstitucionalidad, México, 14 de julio de 2014, http://fundar.org.mx/el-ifai-debe-presentar-accion-de-inconstituciona lidad-en-contra-de-la-ley-de-telecomunicacion-y-radiodifusion/\#.VBnrQvl5OSo (consultada el 13 de septiembre de 2014).

SALAZAR, Grisel, "Comentario a la propuesta de reforma constitucional en materia de transparencia aprobada en 2012 por el Senado", Boletín Mexicano de Derecho Comparado, núm. 137, 2013.

MERINO, Mauricio, "Muchas políticas y un solo derecho", en LóPEZ-AYLLÓN, Sergio (ed.), Democracia, transparencia y Constitución, México, IFAIUNAM, 2006.

"Posicionamiento de los Comisionados del IFAI sobre la inconstitucionalidad de los artículos 30, 189 y 190, fracciones I, II y III de la Ley Federal de Telecomunicaciones y Radiodifusión”, IFAI, México, 13 de agosto de 2014.

"Red por la Rendición de Cuentas", Acción de inconstitucionalidad y Reforma Telecom, http://rendiciondecuentas.org.mx/accion-de-inconstitucionalidad-y-refor ma-telecom/(consultada el 10 de septiembre de 2014). 